\title{
Leukemogenic Fusion Gene (p190 BCR-ABL) Transduction into Hematopoietic Stem/Progenitor Cells in the Common Marmoset
}

\author{
Yan Dong $^{1}$, Seiichiro Kobayashi ${ }^{1}$, Yamin Tian ${ }^{1,2}$, Manabu Ozawa ${ }^{1,2}$, Takafumi Hiramoto ${ }^{2}$, \\ Kiyoko Izawa $^{1}$, Yuansong Bai ${ }^{1}$, Yasushi Soda ${ }^{1}$, Erika Sasaki $^{3}$, Toshio Itoh ${ }^{3}$, Yoshiro Maru ${ }^{4}$, \\ Satoshi Takahashi ${ }^{1}$, Kaoru Uchimaru ${ }^{5}$, Naoki Oyaizu ${ }^{6}$, Arinobu Tojo ${ }^{1}$, Chieko Kai ${ }^{7}, K^{2}$ Knaburo Tani $^{2 *}$ \\ ${ }^{1}$ Division of Molecular Therapy, Institute of Medical Science, The University of Tokyo, Tokyo, Japan; ${ }^{2}$ Department of Molecular \\ Genetics, Medical Institute of Bioregulation, Kyushu University, Fukuoka, Japan; ${ }^{3}$ Central Institute for Experimental Animals, Ka- \\ wasaki, Japan; ${ }^{4}$ Department of Pharmacology, Tokyo Woman's Medical University, Tokyo, Japan; ${ }^{5}$ Department of Hematology/ \\ Oncology, Research Hospital, Institute of Medical Science, The University of Tokyo, Tokyo, Japan; ${ }^{6}$ Department of Laboratory \\ Medicine, Research Hospital, Institute of Medical Science, The University of Tokyo, Tokyo, Japan; ${ }^{7}$ Laboratory Animal Research \\ Center, Institute of Medical Science, The University of Tokyo, Tokyo, Japan. \\ Email: ${ }^{*}$ taniken@bioreg.kyushu-u.ac.jp
}

Received December $9^{\text {th }}, 2011$; revised January $24^{\text {th }}, 2012$; accepted February $16^{\text {th }}, 2012$

\begin{abstract}
Patients with Philadelphia chromosome (p190 BCR-ABL fusion gene)-positive acute lymphoblastic leukemia have a poor prognosis despite intensive therapeutic intervention. In this study, we attempted to develop a leukemia nonhuman primate model that mimics various human systems. Hematopoietic stem/progenitor cells in the common marmoset were transduced with a lentiviral vector containing the p190 BCR-ABL fusion gene by ex vivo transduction or in vivo direct bone marrow injection. In the latter model, BCR-ABL gene expression was maintained for more than one and a half years. One marmoset unexpectedly developed myelofibrosis-like disease. However, none of the marmosets have developed leukemia to date. In conclusion, we successfully achieved sustained p190 BCR-ABL gene expression in vivo. However, a genetic mutation in addition to p190 BCR-ABL may be required for the malignant transformation of hematopoietic stem/progenitor cells in the common marmoset during the short observation period. This novel in vivo approach will help develop a marmoset leukemia model in the future.
\end{abstract}

Keywords: Leukemia; Lentiviral Vector; Myelofibrosis; Common Marmoset

\section{Introduction}

Many preclinical in vivo studies have been conducted in mice because they are easy to breed and their biology and genetics are well-characterized. However, humans and mice differ genetically, pathophysiologically and pharmacokinetically, which makes it difficult to extrapolate the results from mouse models for direct clinical applications in humans. Large animals, especially nonhuman primates, are more closely related to humans. Moreover, because of their long life span, nonhuman primates can be treated and monitored over a long period, which presents opportunities for time-varying sampling of their blood and bone marrow. Thus, the development of non-human primate models that mimic human pathophysiology and pharmacokinetics will significantly further our understanding of human diseases. Particularly,

${ }^{*}$ Corresponding author. genetically modified primates will be a powerful human disease model that can be used to preclinically assess the safety and efficacy of developing drugs.

Currently, Old World primates, such as the rhesus monkey (Macaca mulatta) and cynomolgus monkey (Macaca fascicularis), are commonly used for research [1-3]. However, these primates have several disadvantages, such as a slow sexual maturation period of approximately three years, fewer offspring over the female lifespan, and difficulty in handling.

The common marmoset (Callithrix jacchus) is a small New World primate that has attracted considerable attention as a potential animal for biomedical research $[4,5]$. The common marmoset is small, weighing approximately $350-400 \mathrm{~g}$, relatively easy to breed, has a short gestation period of approximately 144 days, reaches sexual maturity at $12-18$ months, and produces $40-80$ offspring during the female lifespan. Thus, although marmosets are 
not as closely related to humans as apes or Old World primates, they are valuable as a potential primate model of human disease.

In this study, we attempted to establish a marmoset leukemia model by introducing a fusion gene that causes leukemia in humans. The Philadelphia chromosome $(\mathrm{Ph})$ contains one of several forms of BCR and c-ABL gene fusions, and these fusions substantially contribute to the pathogenesis of chronic myelogenous leukemia (CML) and acute lymphoblastic leukemia (ALL). The p190 BCR-ABL fusion gene, in which BCR exon 1 is joined to ABL exon 2 (e1a2) and produces the p190 protein, is detected in $20 \%-35 \%$ of ALL patients, and the prognosis of these patients is particularly poor [6,7]. Several treatments, such as allogeneic hematopoietic stem cell transplantation and novel small molecules that directly target the p190 BCR-ABL fusion gene have been developed to treat this refractory disease [8]. Transduction of the p190 BCR-ABL fusion gene is reportedly sufficient to cause leukemia in mice [9-11]. However, to date, there are no reports of a primate leukemia model. Establishing a marmoset model of this disease will be useful to test the efficacy of current and future treatments. Therefore, we transduced the p190 BCR-ABL fusion gene into marmoset $\mathrm{CD}_{3} 4^{+}$hematopoietic stem/progenitor cells using a lentiviral vector and examined the occurrence of leukemogenic events.

\section{Materials and Methods}

\subsection{Cell Lines}

$\mathrm{Ba} / \mathrm{F} 3$ cells, a mouse interleukin-3 (mIL-3)-dependent hematopoietic cell line, were maintained in RPMI (Invitrogen, Carlsbad, CA, USA) supplemented with $10 \%$ fetal bovine serum (FBS) and $\mathrm{mIL}-3(10 \mathrm{ng} / \mathrm{mL})$ at $37^{\circ} \mathrm{C}$ in $5 \% \mathrm{CO}_{2}$ and passaged twice every week.

\subsection{Animals and Preparation of Bone Marrow and Peripheral Blood Mononuclear Cells}

Common marmosets were purchased from the Division of Animal Experimentation, Central Institute for Experimental Animals (Kawasaki, Japan), and bred at the animal center at our institute. In this study five animals were used including one control marmoset. No. 591 (male, 2 years and 6 months old) and No. 2338 (female, 4 years and 9 months old) were used as ex vivo BCRABL transduction models. No. 2129 (female, 5 years and 7 months old) and No. 2223 (female, 5 years and 3 months old) were used as BCR-ABL direct in vivo injection models. The study protocol was approved by the animal ethical committee of the University of Tokyo.

Bone marrow samples were collected by flushing the femurs of euthanized animals or aspirating the femoral bone marrow with an aspiration needle (Task, Tochigi, Japan). Peripheral blood samples were collected with heparin. Mononuclear cells (MNCs) in each sample were isolated by density-gradient centrifugation with Lymphoprep (Axis-Shield, Oslo, Norway). The cells were frozen in liquid nitrogen until further use.

\subsection{Construction, Production and Transduction of Lentiviral Vector}

Third generation, VSV.G pseudotyped lentiviral vectors were produced by transiently cotransfecting four plasmids into 293T cells as previously described [12]. Briefly, the p190 BCR-ABL fusion gene driven by a CMV or PGK promoter (HIV-CMV/PGK-BCR-ABL) was inserted into the transfer vector [13]. This plasmid was cotransfected into 293T cells using the calcium-phosphate method. The viral supernatant was harvested 48 and 72 hrs post transfection. The viral pellet was collected by ultra-centrifuging the supernatant and then stored at $-80^{\circ} \mathrm{C}$. The DNA titer, which is known to reflect the amount of transducible vector genome, was determined by real-time quantitative PCR as previously described [14]. For transduction, a cell pellet $\left(2 \times 10^{5}\right)$ was mixed and incubated with concentrated viral supernatant $(20 \mu \mathrm{L})$ for 2 hrs in a $37^{\circ} \mathrm{C}$ incubator. The cells were generally infected in vitro with an MOI (multiplicity of infection) of 2.

\subsection{Detection of p190 BCR-ABL Transgene Expression}

RNA extraction and reverse transcription were performed as previously described using an RNA/DNA extraction kit (Qiagen, Hilden, Germany) and SuperScript First-Strand Synthesis System for RT-PCR (Invitrogen). Nested PCR amplification of p190 BCR-ABL was performed using a GeneAmp PCR System 9700 (Applied Biosystems, Foster City, CA, USA) with primers that specifically amplify the e1a2 transcripts. A $50 \mu \mathrm{L}$ reaction mixture containing $2 \mathrm{mM}$ of each dNTP, $25 \mathrm{mM}$ $\mathrm{MgCl}_{2}, 10 \times$ PCR buffer, $0.5 \mu \mathrm{M}$ primers, $1.25 \mathrm{U}$ AmpliTaq Gold (Applied Biosystems) and 10 ng cDNA was subjected to 40 cycles of denaturation $\left(95^{\circ} \mathrm{C}, 30 \mathrm{sec}\right)$, annealing $\left(61^{\circ} \mathrm{C}, 30 \mathrm{sec}\right)$, and extension $\left(72^{\circ} \mathrm{C}, 30 \mathrm{sec}\right)$ and another 40 cycles with the inner primer set of denaturation $\left(95^{\circ} \mathrm{C}, 30 \mathrm{sec}\right)$, annealing $\left(57^{\circ} \mathrm{C}, 30 \mathrm{sec}\right)$, and extension $\left(72^{\circ} \mathrm{C}, 30 \mathrm{sec}\right)$. The final products were analyzed on a $1 \%$ agarose gel stained with ethidium bromide. The outer BCR-ABL primer set was forward primer (5'-CGC TCT CCC TCG CAG AAC TC-3') and reverse primer (5'-GGA GTG TTT CTC CAG ACT GTT GAC TG-3'), while the inner primer set was forward primer (5'-AAC AGT CCT TCG ACA GCA GCA-3') and reverse primer (5'-GCG TGA TGT AGT TGC TTG GGA- 
$\left.3^{\prime}\right)$. Sequencing analysis showed that the amplified products were compatible with the p190 BCR-ABL fusion gene (data not shown). Expression of p190 BCR-ABL protein was confirmed by western blot analysis in our previous report [15]. The glyceraldehyde-3-phosphate dehydrogenase (GAPDH) gene was simultaneously amplified as an internal control. In some experiments, realtime quantitative PCR analysis of p190 BCR-ABL was performed as previously described [16].

\subsection{Enrichment of CD34 ${ }^{+}$Bone Marrow Cells}

Marmoset bone marrow $\mathrm{CD} 34^{+}$cells were isolated with the immunobeads system using streptavidin microbeads (MACS, Miltenyi Biotec, Sunnyvale, CA, USA). Marmoset bone marrow MNCs were prepared from fresh bone marrow samples and stained with a biotin-labeled anti-marmoset CD34 monoclonal antibody (clone MA24) for $30 \mathrm{~min}$ at $4^{\circ} \mathrm{C}$ [17]. The cells were washed and incubated with streptavidin-conjugated microbeads for 15 min at $4^{\circ} \mathrm{C}$. The $\mathrm{CD} 34^{+}$cells were washed and separated using immunomagnetic columns (MACS) according to the manufacturer's instructions.

\subsection{Ex Vivo p190 BCR-ABL Transduction and Autologous Peripheral Blood Stem Cell Transplantation (PBSCT)}

The time course and treatment protocol are described in Table 1. Briefly, $10 \mu \mathrm{g} / \mathrm{kg} / \mathrm{day}$ of recombinant human granulocyte colony-stimulating factor (G-CSF, Roche, Basel, Switzerland) was subcutaneously administered to individual marmosets for five days. Peripheral blood (1 $\mathrm{mL}$ ) was collected daily from the femoral vein of each marmoset for seven consecutive days. MNCs were isolated by Ficoll-Hypaque centrifugation. Red cell lysis was performed when necessary. The cells were frozen using a programmed freezer and stored in liquid nitrogen until use. Ninety milligrams of busulfan (Sigma Aldrich, St Louis, MO, USA) was dissolved in $15 \mathrm{~mL}$ of DMA/ PEG (1:2) solution, and a $6 \mathrm{mg} / \mathrm{mL}$ busulfan solution was made. All marmosets received the busulfan solution $(10 \mathrm{mg} / \mathrm{kg}$ ) from day -3 to day -2 before PBSCT as pre- viously described $[18,19]$.

Three days before transplantation, the MNCs were thawed and incubated overnight in IMDM supplemented with $10 \%$ FBS and human cytokines $(10 \mathrm{ng} / \mathrm{mL} \mathrm{hSCF}$, hIL-3 and hTPO) as previously described with some modifications [12]. After pre-stimulation, the cells were collected and centrifuged. The cell pellet was incubated with the concentrated viral supernatant at $37^{\circ} \mathrm{C}$ in $5 \%$ $\mathrm{CO}_{2}$ for $2 \mathrm{hrs}$. The cells of two marmoset (No. 591 and 2338) were infected with the CMV-p190 BCR-ABL lentiviral vector. Then, the cells were cultured in IMDM supplemented with $10 \%$ FBS and human cytokines (hSCF, hIL-3, hTPO) in 24-well plates for $48 \mathrm{hrs}$. The transduced cells were collected, filtered with $40 \mu \mathrm{m}$ nylon mesh, washed with serum-free IMDM and suspended in $1.5 \mathrm{~mL}$ normal saline. The cells $\left(2 \times 10^{6}\right)$ were transplanted via the femoral vein using a syringe and $27 \mathrm{G}$ needle.

\subsection{Direct Injection of Lentiviral Vectors into the Bone Marrow}

The time course and treatment protocol are described in Table 2. Briefly, marmosets received $25 \mathrm{mg} /$ body of 5-fluorouracil (Kyowa Hakko Kirin, Tokyo, Japan) on day -5 and prednisolone from day -3 to day 1 . After anesthesia, in vivo transduction of bone marrow cells was performed by directly injecting the viral supernatant into the bone marrow cavity using an aspiration needle on day 0. One marmoset (No. 2129) received the CMV-p190 BCR-ABL lentiviral vector, whereas the other (No. 2223) received the PGK-p190 BCR-ABL lentiviral vector. All marmosets received both oral fluconazol ( $2 \mathrm{mg} /$ body/day) and intramuscular injections of ampicillin $(10 \mathrm{mg} / \mathrm{body} /$ day) from day -5 to day 7 and pentamidine $(1.5 \mathrm{mg} /$ body/day) once on day -5 .

\subsection{Colony Formation Assay}

A colony formation assay (progenitor cell assay) was performed as previously described with minor modifications [17]. Bone marrow cells were washed twice, plated in methylcellulose containing human hematopoietic

Table 1. Time coure and treatment of ex vivo BCR-ABL transduction method.

\begin{tabular}{|c|c|c|c|c|c|c|c|c|c|c|c|c|c|c|c|c|}
\hline Treatment & -14 & -13 & -12 & -11 & -10 & -9 & -8 & -7 & -6 & -5 & -4 & -3 & -2 & -1 & 0 & (days) \\
\hline G-CSF (10 $\mu \mathrm{g} /$ body) & $\bullet$ & $\bullet$ & $\bullet$ & $\bullet$ & $\bullet$ & & & & & & & & & & & \\
\hline PBMC collection & & & & & $\bullet$ & $\bullet$ & $\bullet$ & $\bullet$ & $\bullet$ & $\bullet$ & $\bullet$ & & & & & \\
\hline Busulfan (10 mg/body) & & & & & & & & & & & & $\bullet$ & $\bullet$ & & & \\
\hline $\begin{array}{l}\text { ex vivo gene transduction (p190 } \\
\text { BCR-ABL) }\end{array}$ & & & & & & & & & & & & & & $\bullet$ & & \\
\hline PBSCT & & & & & & & & & & & & & & & $\nabla$ & \\
\hline
\end{tabular}

G-CSF: granulocyte colony stimulationg factor; PBMC: peripheral blood mononuclear cell; PBSCT: peripheral blood stem cell transplantation. 
Table 2. Time coure and treatment of BCR-ABL direct in vivo injection method.

\begin{tabular}{|c|c|c|c|c|c|c|c|c|c|c|c|c|c|c|}
\hline Treatment & -5 & -4 & -3 & -2 & -1 & 0 & 1 & 2 & 3 & 4 & 5 & 6 & 7 & (days) \\
\hline 5FU (25 mg/body) & - & & & & & & & & & & & & & \\
\hline PSL (8 mg/body) & & & - & - & - & & & & & & & & & \\
\hline PSL (4 mg/body) & & & & & & - & & & & & & & & \\
\hline PSL (2 mg/body) & & & & & & & - & & & & & & & \\
\hline BM injection (p190 BCR-ABL) & & & & & & $\boldsymbol{\nabla}$ & & & & & & & & \\
\hline Pentamidine ( $1.5 \mathrm{mg} /$ body $)$ & - & & & & & & & & & & & & & \\
\hline ABPC (10 mg/body) & - & - & - & - & - & - & - & - & - & - & - & - & - & \\
\hline FCZ (2 mg/body) & - & - & - & - & - & - & - & - & - & - & - & - & - & \\
\hline
\end{tabular}

5FU: 5-fluorouracil, PSL: predonisolone, BM: bone marrow, ABPC: ampicillin, FCZ: fluconazole

cytokines (Methocult GF+, StemCell Technologies, Vancouver, $\mathrm{BC}$, Canada) and incubated at $37^{\circ} \mathrm{C}$ in $5 \% \mathrm{CO}_{2}$. Then, $1.5 \times 10^{3}$ MACS-sorted CD34 $4^{+}$cells or $3 \times 10^{4}$ non-sorted cells were plated in one dish. On day 14 , individual colonies were picked to identify BCR-ABL gene transduction by RT-PCR and examined by May-Giemsa staining.

\section{Results}

\subsection{Lentiviral Vector Expressing p190 BCR-ABL Functionally and Efficiently Transduced Hematopoietic Stem/Progenitor Cells}

First, we produced third generation VSV.G pseudotyped lentiviral vectors expressing the p190 BCR-ABL fusion gene (HIV-CMV/PGK-BCR-ABL). Plasmids including the lentiviral transfer vector were transduced into $293 \mathrm{~T}$ cells by the calcium phosphate method. After 48 and 72 hrs, the viral supernatants were collected and ultra-centrifuged. The DNA titers of HIV-CMV-BCR-ABL and HIV-PGK-BCR-ABL were $5.59 \times 10^{7} / \mathrm{ml}$ and $2.53 \times$ $10^{8} / \mathrm{ml}$, respectively. To determine that the vector functions properly, $\mathrm{Ba} / \mathrm{F} 3$ cells, a mIL-3-dependent murine hematopoietic cell line, were transduced with this vector and cultured without mIL-3. These cells rapidly expanded after 12 days, indicating that p190 BCR-ABL gene expression allowed the $\mathrm{Ba} / \mathrm{F} 3$ cells to grow autonomously regardless of the promoter used (Figure 1(a)). RT-PCR confirmed that p190 BCR-ABL was expressed in the transduced $\mathrm{Ba} / \mathrm{F} 3$ cells (Figure 1(b)). We then performed quantitative RT-PCR (Figure 1(c)). Although the MOI of the lentiviral vector was not high, p190 BCR$\mathrm{ABL}$ expression was detected in the $\mathrm{Ba} / \mathrm{F} 3$ cell line. Next, to check whether marmoset hematopoietic stem/progenitor cells were efficiently transduced with the lentiviral vector, MACS-sorted bone marrow $\mathrm{CD} 34^{+}$cells were transduced with the lentiviral vector (HIV-CMV/PGKBCR-ABL) and subjected to the colony formation assay (Figure 1(d)). In more than $80 \%$ of colonies examined, p190 BCR-ABL transduction was detected regardless of the promoter. Taken together, the above findings indicate that this oncogene was efficiently transduced into marmoset stem/progenitor cells.

\subsection{Ex Vivo BCR-ABL Transduction Method}

To establish a marmoset leukemia model, we first tried the ex vivo BCR-ABL transduction method (Table 1). After mobilizing the hematopoietic stem/progenitor cells by administering G-CSF, peripheral blood MNCs were collected according to the schedule in Table 1. The collected cells were pre-cultured with cytokines $(10 \mathrm{ng} / \mathrm{ml}$ hSCF, hIL-3 and hTPO) to improve the transduction efficiency. After the cells were transduced with the lentiviral vector containing the 190 BCR-ABL fusion gene $e x$ vivo, they were transplanted into common marmosets that were previously treated with pre-conditioning busulfan (Table 1). On days 28 and 56 post transplantation, BCRABL expression was detected by RT-PCR in the peripheral blood MNCs of two marmosets (Figure 2(a), upper). The time course for BCR-ABL expression after transplantation is shown in Figure 2(a) (lower). Although we expected stable BCR-ABL expression, BCR-ABL expression disappeared after days 56 and 100 in two marmosets. Because this result was thought to partially result from low-level transgene expression due to ineffective gene transduction in hematopoietic stem/progenitor cells, we changed the gene transduction method.

\subsection{In Vivo BCR-ABL Direct Transduction Method}

Previous reports showed that directly injecting lentiviral vectors in vivo resulted in stable gene expression [20]. 


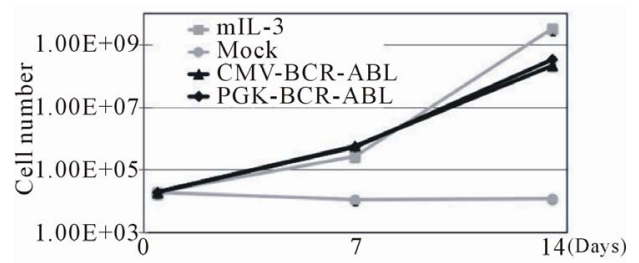

(a)

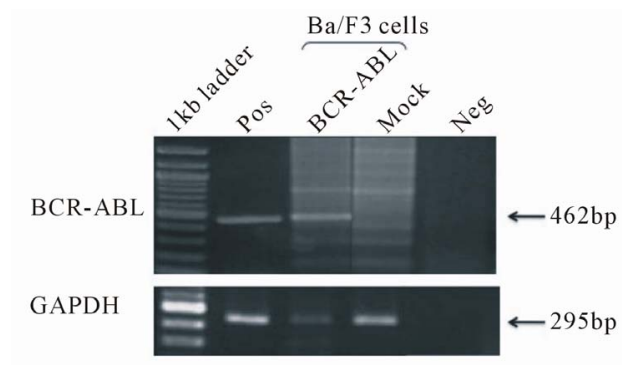

(b)

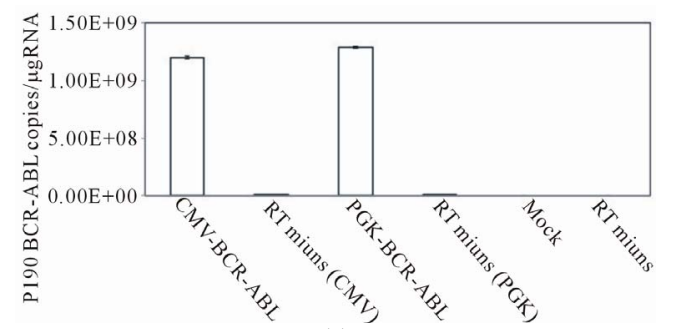

(c)

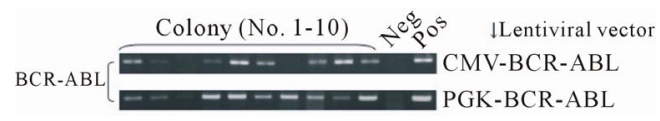

(d)

Figure 1. (a) Ba/F3, a murine hematopoietic cell line that is dependent on mouse interleukin-3 (mIL-3), was transduced with the p190 BCR-ABL lentiviral vector (HIV-CMV/ PGKBCR-ABL) and cultured without mIL-3. As positive and negative controls, mock transfected cells were cultured with or without mIL-3. The number of live cells was determined by the trypan blue exclusion method. All experiments were done in triplicate and also repeated three independent times, and data were plotted as mean $\pm \mathrm{SD}$; (b) Detection of the BCR-ABL fusion gene in transduced Ba/F3 cells. Three days after lentiviral transduction, RT-PCR for the BCRABL gene was performed in BCR-ABL- or mock-transduced cell lines. Pos: positive control (KOPN30 cell line harbouring p190 BCR-ABL), Neg: negative control (ddw: deionized distilled water); (c) Quantitative analysis of transduced p190 BCR-ABL fusion gene expression. Three days after lentiviral transduction, quantitative RT-PCR for p190 BCR-ABL was performed. RT minus indicates the control PCR reaction without reverse transcriptase; (d) Lentiviral transduction of the BCR-ABL gene into colony-forming hematopoietic stem/progenitor cells. MACS-sorted marmoset $\mathrm{CD}^{+} 4^{+}$cells were transduced with the lentiviral vector expressing p190 BCR-ABL under a CMV or PGK promoter, and then $1.5 \times 10^{3}$ cells were plated in methylcellulose containing human hematopoietic growth factors. After 14 days of culture, colonies were randomly picked and examined for BCR-ABL gene expression by RT-PCR.

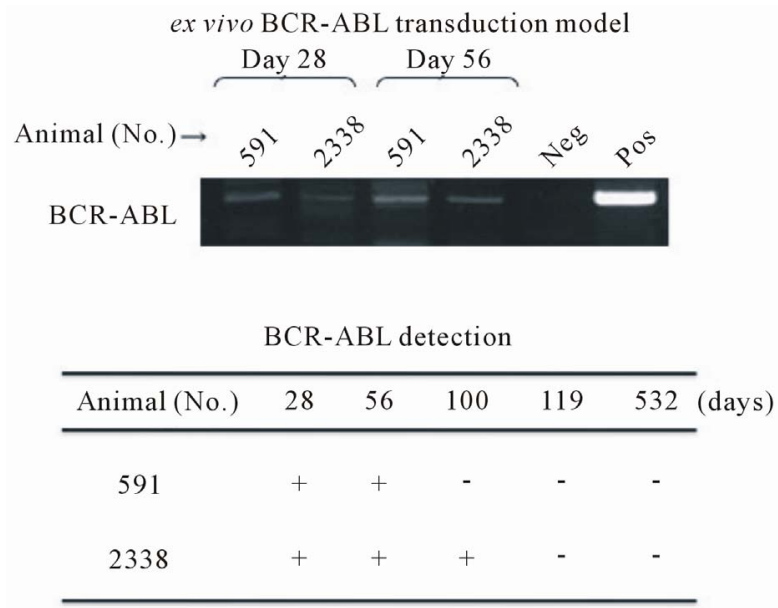

(a)

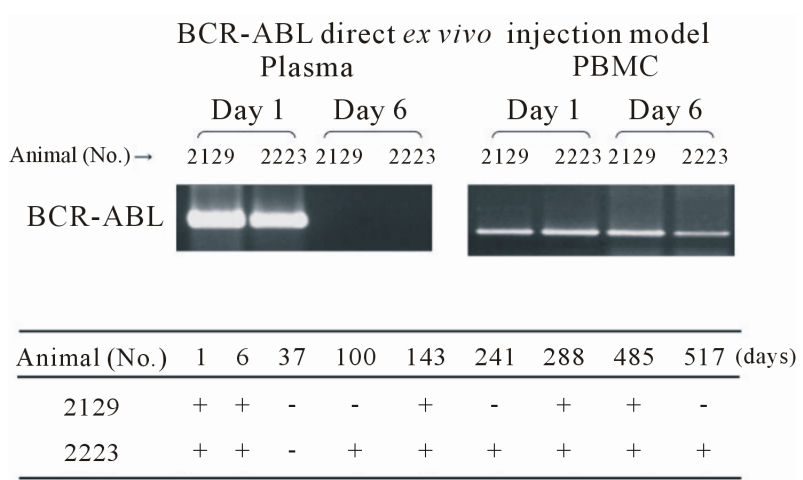

(b)

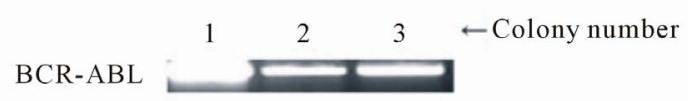

(c)

Figure 2. (a) Detection of the BCR-ABL fusion gene with the ex vivo BCR-ABL transduction method. Upper: RTPCR of the BCR-ABL fusion gene in samples on day 28 and 56 after the BCR-ABL-transduced $\mathrm{CD}_{4}{ }^{+}$cells were transplanted. Lower: detection of BCR-ABL in samples from day 28 to 532 in two marmosets. BCR-ABL expression disappeared in two marmosets after day 56 and 100. GAPDH expression was confirmed for all samples (data not shown). No. 591 and No. 2338: CMV-p190 BCR-ABL; (b) Detection of BCR-ABL fusion gene with the in vivo BCR-ABL direct transduction method. Upper: RT-PCR of the BCR-ABL fusion gene in plasma and PBMC samples on days 1 and 6. Lower: detection of BCR-ABL in samples from day 1 to day 517 in two marmosets. Compared to the ex vivo BCR-ABL transduction method, two marmosets maintained long-term BCR-ABL expression. No. 2129: CMV-p190 BCR-ABL. No. 2223: PGK-p190 BCR-ABL; (c) Detection of the BCR-ABL fusion gene in colony-forming hematopoietic stem/progenitor cells. Bone marrow MNCs were isolated from marmoset No. 2223 on day 517, and $3 \times 10^{4}$ cells were plated in methylcellulose containing several human hematopoietic growth factors. After 14 days of culture, colonies were randomly picked and examined for the BCR-ABL gene. Three out of nine colonies were positive for BCR-ABL. 
Therefore, we administered an immunosuppressive pretreatment therapy consisting of 5-fluouracil and prednisolone and then injected the lentiviral vector into the bone marrow cavity (Table 2). BCR-ABL was detected in the plasma on day 1 but not day 6 . In contrast, BCR$\mathrm{ABL}$ was detected in peripheral blood MNCs on day 1 and 6 in two marmosets. Figure 2(b) (lower) shows the time course of BCR-ABL expression after injection. With this in vivo BCR-ABL direct transduction method, BCR-ABL expression was sustained in two marmosets (No. 2129: positive until day 485, No. 2223: positive until day 517). To determine if the p190 BCR-ABL fusion gene was successfully transduced into hematopoietic stem/progenitor cells, we performed a colony formation assay. Thirty thousand bone marrow MNCs were isolated from marmoset No. 2223 on day 517 and plated in methylcellulose. After 14 days of culture, random colonies were examined for BCR-ABL gene expression. Three of nine colonies were positive for BCR-ABL expression (Figure 2(c)). In the same experiment, all colonies for the control marmoset were negative for BCR-ABL expression (data not shown).

\subsection{Myelofibrosis in a Marmoset That Was Directly Transduced with BCR-ABL in Vivo}

Marmoset No. 2223, which received a direct in vivo injection and maintained BCR-ABL expression, became lethargic and lost weight. A blood cell count indicated anemia and thrombocytopenia (Figure 3(a)). This marmoset was sacrificed on day 686 post injection and examined pathologically. BCR-ABL expression was detected in the spleen, liver, kidney, heart and peripheral blood MNCs by RT-PCR. However, the bone marrow sample was negative for BCR-ABL. Hematoxylin-Eosin staining of the bone marrow showed that the bone marrow cavity was replaced by a marked noncellular component (Figure 3(b)). Bone marrow fibrosis was confirmed by Masson staining. An examination of the liver revealed extramedullary hematopoiesis. Naphthol AS-D chloroacetate (ASD) and Myeloperoxidase (MPO) staining confirmed that the cells were of myeloid lineage (Figure 3(c)).

\section{Discussion}

Previously, we reperted the usefulness of the common marmoset as a hematopoietic stem/progenitor cell transplantation model, analytic results of major histocompatibility antigens, and the production of anti-marmoset CD34 monoclonal antibodies $[4,17,21,22]$. These studies helped to establish and analyze a primate disease model. In this study, we lentivirally transduced common marmoset hematopoietic cells with the p190 BCR-ABL fu-

\begin{tabular}{cccc}
\hline Animal (No.) & $\begin{array}{c}\text { RBC } \\
\left(\times 10^{4} / \mu \mathrm{L}\right)\end{array}$ & $\begin{array}{c}\text { WBC } \\
\left(\times 10^{2} / \mu \mathrm{L}\right)\end{array}$ & $\begin{array}{c}\text { Plt } \\
\left(\times 10^{4} / \mu \mathrm{L}\right)\end{array}$ \\
\hline BCR-ABL (2223) & 175 & 13.9 & 14.1 \\
Normal & $623 \pm 74$ & $9.7 \pm 3.2$ & $65.0 \pm 17.0$ \\
(range) & $(373-717)$ & $(3.3-17.4)$ & $(40.5-111.2)$ \\
\hline
\end{tabular}

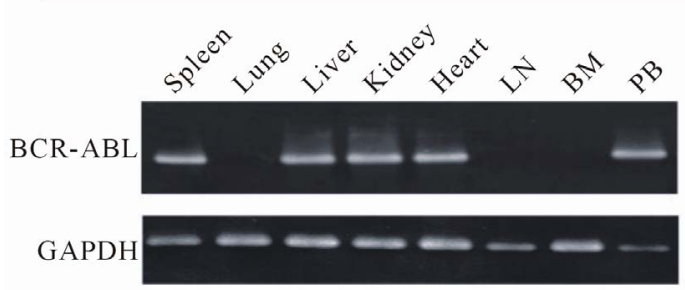

(a)

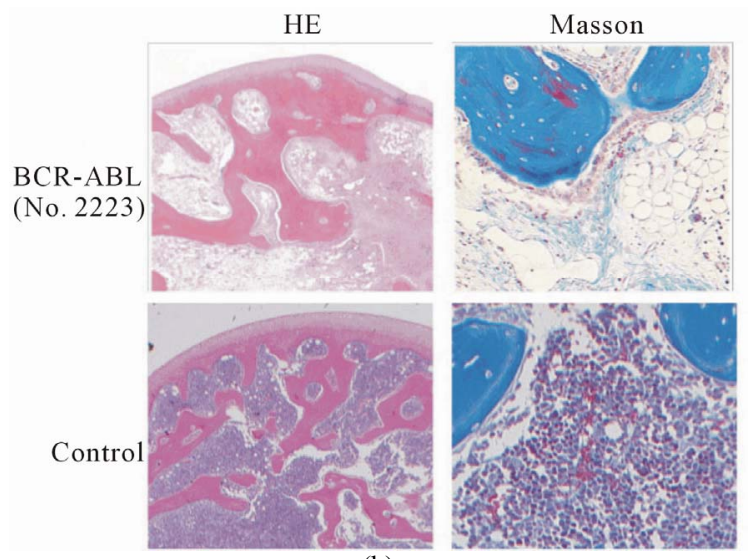

(b)

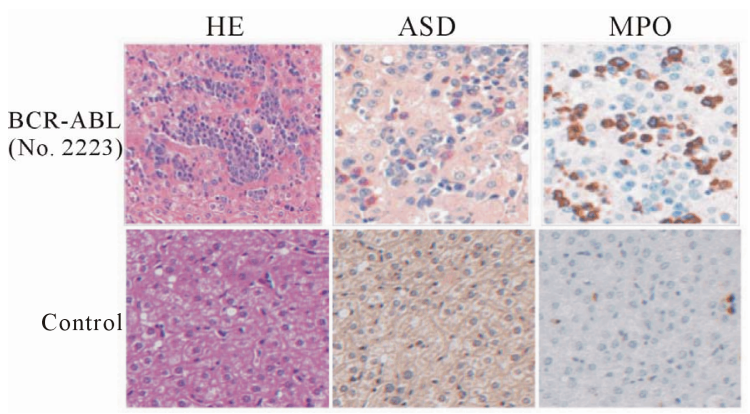

(c)

Figure 3. Pathological examination of marmoset No. 2223 (transduced using the in vivo BCR-ABL direct transduction method) with myelofibrosis-like disease. (a) Upper: Peripheral blood count of No. 2223 on day -7 before sacrifice. Data on the blood cell count of healthy marmosets were obtained from a textbook. Lower: The marmoset was sacrificed and pathologically examined on day 686 after p190 BCR-ABL was directly injected into the bone marrow. BCR-ABL gene expression was detected by a RT-PCR method in several organs. No. 2223: PGK-p190 BCR-ABL; (b) Left: Hematoxylin-Eosin (HE) staining of the bone marrow. Right: Masson staining. Bone marrow fibrosis is stained in blue. Upper: Experimental marmoset (No. 2223). Lower: Control marmoset; (c) Extramedullary hematopoiesis in the liver in the experimental marmoset (upper). ASD: Naphthol AS-D chloroacetate stain, MPO: Myeloperoxidase stain. 
sion gene using either an ex vivo BCR-ABL transduction method or in vivo BCR-ABL direct transduction method. Then, we examined the expression of the fusion oncogene in transduced progenitor cells in vivo and monitored the marmosets for leukemogenic events.

With the ex vivo BCR-ABL transduction method, BCR-ABL expression was not detected by RT-PCR after day 100 (Figure 2(a)). This lack of sustained expression may result from a low gene transduction efficiency of hematopoietic stem/progenitor cells even though the high transduction efficiency at progenitor levels. Additionally, the transduced cells may have been immunologically rejected. Anti-human G-CSF neutralizing antibodies appeared in the transplanted marmosets even with an immunosuppressive pre-conditioning regimen (data not shown). The presence of these antibodies supports the latter possibility. Majority of the marmosets used in this study were four to six years old, which is an immunologically competent and equivalent to an adult human. Treating the marmosets with immune suppressants might solve this problem.

Previously, our group successfully transduced G-CSFmobilized hematopoietic stem/progenitor cells in a marmoset model with the MDR1 gene using a retroviral vector [21]. In this study, a consistent increase in progenitor cells in the peripheral blood was observed using the same G-CSF mobilization protocol. Retroviral vectors mainly transduce dividing cells. In contrast, lentiviral vectors transduce both dividing and non-dividing cells $[12,20]$. And recent reports showed that the retroviral vector, but not lentiviral vector, is integrated near transcriptional genes and induce leukemia [23]. Moreover, in a previous study, we successfully transduced cord blood hematopoietic stem/progenitor cells using a lentiviral vector [12]. For these reasons, we chose a lentiviral vector to transduce $\mathrm{p} 190 \mathrm{BCR}-\mathrm{ABL}$ in order to obtain a high transduction efficiency. However, the p190 BCR-ABL gene is approximately 6 kilobase pairs in length, and its large size hinders the production of a high-titer lentiviral vector. This limitation may be one reason why BCR$\mathrm{ABL}$ was expressed for a limited time with the ex vivo BCR-ABL transduction method (Figure 2(a)).

This was our first attempt to directly inject a lentiviral vector in vivo into the bone marrow of common marmosets, although a previous study reported efficient gene transduction by direct injection into the central nervous system of rats [24]. BCR-ABL was detected in the plasmaon day 1 but not day 6 . It is likely that vectors injected into the bone marrow, which is rich in blood vessels, transiently leaked into the circulation. Of note, we observed long-term BCR-ABL expression in hematopoietic cells (Figure 2(b)). Further optimization of the experimental procedures, such as altering the pre-conditioning regimen, using a higher titer vector, and treating with immunosuppressive drugs after injecting the lentiviral vector, might be effective to obtain stable gene expression in hematopoietic stem/progenitor cells in vivo.

To date, mouse models have been predominantly used to study human cancers [25]. However, primates are more genetically related to humans than rodents. For this reason, much effort has focused on establishing a primate model that can be used to more precisely evaluate new cancer therapies in pre-clinical studies. However, thus far, there have been no successful reports of a primate model that mimics human cancers, and this study also faced challenges. The primary reason for these difficulties may be because primate and rodent hematopoietic stem/progenitor cells have different susceptibilities to oncogene transduction [26,27]. In gene therapy clinical trials in France for X chromosome-linked severe combined immune deficiency, leukemia developed two to three years after the common $\gamma$ chain receptor gene was transduced into hematopoietic stem/progenitor cells [26-28]. In contrast, in a mouse model of oncogene transduction, the duration of developing leukemia is generally less than one year [9-11]. Therefore, these findings support the hypothesis mentioned above.

Moreover, the susceptibility to malignant transformation by each oncogene reportedly differs based on age in humans. For example, for the chromosomal translocations in ALL, MLL-AF4 is dominant in infants, TELAML1 in children, and BCR-ABL in adults [29]. Furthermore, cord blood cells were used in all previous reports of BCR-ABL transduction into human hematopoietic stem/progenitor cells in a SCID mouse model [30]. There have been no studies that used adult hematopoietic progenitor cells. In this study, all of the marmosets were adults. Considering these findings, it will be important to consider using younger marmosets in future studies.

Furthermore, it is well known that multiple genetic mutations are required for leukemogenesis [31]. The number of required gene mutations may not be the same between primates and rodents. In the marmoset model, subsequent gene mutations in addition to p190 BCR$\mathrm{ABL}$ may be required for malignant transformation [32]. Thus, it may be necessary to test the cotransduction of p190 BCR-ABL and another oncogene, mutated tumor suppressor gene, or anti-apoptosis gene in order to achieve leukemogenesis in the marmoset model.

Unexpectedly, one marmoset that was transduced using the in vivo BCR-ABL direct transduction method developed myelofibrosis-like disease (Figures 3(a)-(c)). BCR-ABL gene expression was detected in various organs. However, BCR-ABL was not expressed in the lung, lymph nodes and bone marrow. BCR-ABL expression could be detected where extramedullar hematopoiesis 
was observed (liver and spleen) and in organs rich in blood perfusion (heart, kidney and peripheral blood). These differences might contribute to the observed tissue specificities, although this is speculative because the data are only from one marmoset. Bone marrow was negative for BCR-ABL. We believe that our inability to detect BCR-ABL expression in this sample was because we could obtain insufficient hematopoietic cells from the fibrotic bone marrow. Recently, a mutation in JAK2 gene was reported to cause myelofibrosis [33]. We hypothesized that the lentiviral vector inserted into the host genome and unregulated the expression of genes such as JAK2. We performed LAM-PCR (linear amplificationmediated PCR), which identifies the sequence flanking the integrated vector genome, to identify the unregulated gene that may be responsible for myelofibrosis [34]. However, due to the insufficient bone marrow samples, this attempt was unsuccessful. If the phenomenon is reproduced in other marmosets, further analyses will be required to understand this pathology.

In conclusion, we stably expressed an oncogene in vivo in a marmoset model, although several steps may be required to develop hematological malignancy in this model. The results provide information that can be used to establish a marmoset disease model in which hematopoietic stem/progenitor cells are targeted for oncogene delivery.

\section{Acknowledgements}

We thank Dr. Hajime Ishii (Central Institute for Experimental Animals, Kawasaki, Japan) for advice on common marmosets, Dr. Hiroyuki Miyoshi (Bioresource Center, RIKEN, Tsukuba, Japan) for providing the lentiviral vector system and Dr. Yoshikazu Sugimoto (Keio University, Tokyo, Japan) for performing LAM-PCR. We thank Mr. Keisuke Takahashi, Ms. Sanae Suzuki and members of our laboratory for assistance. We thank Dr. Kazuaki Yokoyama and Ms. Nozomi Yusa (The University of Tokyo) for technical assistance with the p190 BCR-ABL quantitative RT-PCR. We thank Dr. Nobukazu Watanabe (The University of Tokyo) for technical assistance with flow cytometry. Finally, we thank the Iwaki Scholarship foundation for helping with the overseas studies of Y.D.

This study was supported by the Ministry of Education, Culture, Sports, Science and Technology and the Ministry of Health, Labour and Welfare of Japan.

\section{REFERENCES}

[1] R. E. Donahue and C. E. Dunbar, "Update on the Use of Nonhuman Primate Models for Preclinical Testing of Gene Therapy Approaches Targeting Hematopoietic Cells,"
Human Gene Therapy, Vol. 12, No. 6, 2001, pp. 607-617. doi:10.1089/104303401300057289

[2] D. W. Emery, R. G. Andrews and T. Papayannopoulou, "Differences among Nonhuman Primates in Susceptibility to Bone Marrow Progenitor Transduction with Retrovirus Vectors," Gene Therapy, Vol. 7, No. 5, 2000, pp. 359-367. doi:10.1038/sj.gt.3301107

[3] H. P. Kiem, S. Sellers, B. Thomasson, J. C. Morris, J. F. Tisdale, P. A. Horn, P. Hematti, R. Adler, K. Kuramoto, B. Calmels, A. Bonifacino, J. Hu, C. von Kalle, M. Schmidt, B. Sorrentino, A. Nienhuis, C. A. Blau, R. G. Andrews, R. E. Donahue and C. E. Dunbar, "Long-Term Clinical and Molecular Follow-Up of Large Animals Receiving Retrovirally Transduced Stem and Progenitor Cells: No Progression to Clonal Hematopoiesis or Leukemia," Molecular Therapy, Vol. 9, No. 3, 2004, pp. 389 395. doi:10.1016/j.ymthe.2003.12.006

[4] H. Hibino, K. Tani, K. Ikebuchi, M. S. Wu, H. Sugiyama, Y. Nakazaki, T. Tanabe, S. Takahashi, A. Tojo, S. Suzuki, Y. Tanioka, Y. Sugimoto, T. Nakahata and S. Asano, "The Common Marmoset as a Target Preclinical Primate Model for Cytokine and Gene Therapy Studies," Blood, Vol. 93, No. 9, 1999, pp. 2839-2848.

[5] E. Sasaki, H. Suemizu, A. Shimada, K. Hanazawa, R. Oiwa, M. Kamioka, I. Tomioka, Y. Sotomaru, R. Hirakawa, T. Eto, S. Shiozawa, T. Maeda, M. Ito, R. Ito, C. Kito, C. Yagihashi, K. Kawai, H. Miyoshi, Y. Tanioka, N. Tamaoki, S. Habu, H. Okano and T. Nomura, "Generation of Transgenic Non-Human Primates with Germline Transmission," Nature, Vol. 459, No. 7246, 2009, pp. 523-527. doi:10.1038/nature08090

[6] M. Arico, M.G. Valsecchi, B. Camitta, M. Schrappe, J. Chessells, A. Baruchel, P. Gaynon, L. Silverman, G. Janka-Schaub, W. Kamps, C. H. Pui and G. Masera, "Outcome of Treatment in Children with Philadelphia Chromosome-Positive Acute Lymphoblastic Leukemia," New England Journal of Medicine, Vol. 342, No. 14, 2000, pp. 998-1006. doi:10.1056/NEJM200004063421402

[7] E. A. Copelan and E. A. McGuire, "The Biology and Treatment of Acute Lymphoblastic Leukemia in Adults," Blood, Vol. 85, No. 5, 1995, pp. 1151-1168.

[8] O. G. Ottmann, B. J. Druker, C. L. Sawyers, J. M. Goldman, J. Reiffers, R. T. Silver, S. Tura, T. Fischer, M. W. Deininger, C. A. Schiffer, M. Baccarani, A. Gratwohl, A. Hochhaus, D. Hoelzer, S. Fernandes-Reese, I. Gathmann, R. Capdeville and S. G. O'Brien, "A Phase 2 Study of Imatinib in Patients with Relapsed or Refractory Philadelphia Chromosome-Positive Acute Lymphoid Leukemias," Blood, Vol. 100, No. 6, 2002, pp. 1965-1971. doi:10.1182/blood-2001-12-0181

[9] N. Heisterkamp, G. Jenster, J. Ten Hoeve, D. Zovich, P. K. Pattengale and J. Groffen, "Acute Leukaemia in bcr/ abl Transgenic Mice," Nature, Vol. 344, No. 6263, 1990, pp. 251-253. doi: $10.1038 / 344251 \mathrm{a} 0$

[10] S. Li, R. L. Ilaria Jr., R. P. Million, G. Q. Daley and R. A. Van Etten, "The P190, P210, and P230 forms of the $\mathrm{BCR} / \mathrm{ABL}$ Oncogene Induce a Similar Chronic Myeloid Leukemia-Like Syndrome in Mice But Have Different 
Lymphoid Leukemogenic Activity," Journal of Experimental Medicine, Vol. 189, No. 9, 1999, pp. 1399-1412. doi:10.1084/jem.189.9.1399

[11] J. W. Voncken, S. Griffiths, M. F. Greaves, P. K. Pattengale, N. Heisterkamp and J. Groffen, "Restricted Oncogenicity of BCR/ABL p190 in Transgenic Mice," Cancer Research, Vol. 52, No. 16, 1992, pp. 4534-4539.

[12] Y. Bai, Y. Soda, K. Izawa, T. Tanabe, X. Kang, A. Tojo, H. Hoshino, H. Miyoshi, S. Asano and K. Tani, "Effective Transduction and Stable Transgene Expression in Human Blood Cells by a Third-Generation Lentiviral Vector," Gene Therapy, Vol. 10, No. 17, 2003, pp. 14461457. doi:10.1038/sj.gt.3302026

[13] Y. Inoue, A. Tojo, R. Sekine, Y. Soda, S. Kobayashi, A. Nomura, K. Izawa, T. Kitamura, T. Okubo and K. Ohtomo, "In Vitro Validation of Bioluminescent Monitoring of Disease Progression and Therapeutic Response in Leukaemia Model Animals," European Journal of Nuclear Medicine and Molecular Imaging, Vol. 33, No. 5, 2006, pp. 557-565. doi:10.1007/s00259-005-0048-4

[14] L. Sastry, T. Johnson, M. J. Hobson, B. Smucker and K. Cornetta, "Titering Lentiviral Vectors: Comparison of DNA, RNA and Marker Expression Methods," Gene Therapy, Vol. 9, No. 17, 2002, pp. 1155-1162. doi:10.1038/sj.gt.3301731

[15] A. Tojo, M. Futami, T. Hatano, Y. Soda, S. Kobayashi and M. Miyagishi, "RNAi-Mediated Silencing of p190 (Bcr-Abl) Inactivates Stat5 and Cooperates with Imatinib Mesylate and 17-Allylamino-17-demetoxygeldanamycin in Selective Killing of p190(Bcr-Abl)-Expressing Leukemia Cells," Leukemia, Vol. 22, No. 6, 2008, pp. 11311138. doi:10.1038/leu.2008.60

[16] M. Towatari, M. Yanada, N. Usui, J. Takauchi, S. I, M. Takeuchi, F. Yagasaki, Y. Kawai, S. Miyawaki, S. Ohtake, J. I. K. Matsuo, T. Naoe, R. Ohno and J. A. L. S. Grp, "Combination of Intensive Chemotherapy and Imatinib Can Rapidly Induce High-Quality Complete Remission for a Majority of Patients with Newly Diagnosed BCR-ABL-Positive Acute Lymphoblastic Leukemia," Blood, Vol. 104, No. 12, 2004, pp. 3507-3512. doi:10.1182/blood-2004-04-1389

[17] K. Izawa, K. Tani, Y. Nakazaki, H. Hibino, H. Sugiyama, A. Kawasaki, E. Sasaki, C. Nishioka, H. Ishii, Y. Soda, H. Yagita, Y. Tanioka, A. Tojo and S. Asano, "Hematopoietic Activity of Common Marmoset CD34 Cells Isolated by a Novel Monoclonal Antibody MA24," Experimental Hematology, Vol. 32, No. 9, 2004, pp. 843-851. doi:10.1016/j.exphem.2004.06.007

[18] A. Aiuti, S. Slavin, M. Aker, F. Ficara, S. Deola, A. Mortellaro, S. Morecki, G. Andolfi, A. Tabucchi, F. Carlucci, E. Marinello, F. Cattaneo, S. Vai, P. Servida, R. Miniero, M. G. Roncarolo and C. Bordignon, "Correction of ADA-SCID by Stem Cell Gene Therapy Combined with Nonmyeloablative Conditioning," Science, Vol. 296, No. 5577, 2002, pp. 2410-2413. doi:10.1126/science.1070104

[19] M. B. Bradley, P. Satwani, L. Baldinger, E. Morris, C. van de Ven, G. Del Toro, J. Garvin, D. George, M. Bhatia, E. Roman, L. A. Baxter-Lowe, J. Schwartz, E. Qualter, R. Hawks, K. Wolownik, S. Foley, O. Militano, J. Leclere,
Y. K. Cheung and M. S. Cairo, "Reduced Intensity Allogeneic Umbilical Cord Blood Transplantation in Children and Adolescent Recipients with Malignant and Non-Malignant Diseases," Bone Marrow Transplant, Vol. 40, No. 7, 2007, pp. 621-631. doi:10.1038/sj.bmt.1705785

[20] L. Naldini, U. Blomer, P. Gallay, D. Ory, R. Mulligan, F. H. Gage, I. M. Verma and D. Trono, "In Vivo Gene Delivery and Stable Transduction of Nondividing Cells by a Lentiviral Vector," Science, Vol. 272, No. 5259, 1996, pp. 263-267. doi:10.1126/science.272.5259.263

[21] H. Hibino, K. Tani, H. Sugiyama, S. Suzuki, M. S. Wu, K. Izawa, H. Hase, Y. Nakazaki, T. Tanabe, J. Ooi, T. Izeki, A. Tojo, I. Saitoh, Y. Tanioka and S. Asano, "Haematopoietic Progenitor Cells from the Common Marmoset as Targets of Gene Transduction by Retroviral and Adenoviral Vectors," European Journal of Haematology, Vol. 66, No. 4, 2001, pp. 272-280. doi:10.1034/j.1600-0609.2001.066004272.x

[22] M. S. Wu, K. Tani, H. Sugiyama, H. Hibino, K. Izawa, T. Tanabe, Y. Nakazaki, H. Ishii, J. Ohashi, H. Hohjoh, T. Iseki, A. Tojo, Y. Nakamura, Y. Tanioka, K. Tokunaga and S. Asano, "MHC (Major Histocompatibility Complex)-DRB Genes and Polymorphisms in Common Marmoset," Journal of Molecular Evolution, Vol. 51, No. 3, 2000, pp. 214-222.

[23] E. Montini, D. Cesana, M. Schmidt, F. Sanvito, M. Ponzoni, C. Bartholomae, L. Sergi Sergi, F. Benedicenti, A. Ambrosi, C. Di Serio, C. Doglioni, C. von Kalle and L. Naldini, "Hematopoietic Stem Cell Gene Transfer in a Tumor-Prone Mouse Model Uncovers Low Genotoxicity of Lentiviral Vector Integration," Nature Biotechnology, Vol. 24, No. 6, 2006, pp. 687-696. doi:10.1038/nbt1216

[24] L. Naldini, U. Blomer, F. H. Gage, D. Trono and I. M. Verma, "Efficient Transfer, Integration, and Sustained Long-Term Expression of the Transgene in Adult Rat Brains Injected with a Lentiviral Vector," Proceedings of the National Academy of Sciences of the United States of America, Vol. 93, No. 21, 1996, pp. 11382-11388. doi:10.1073/pnas.93.21.11382

[25] B. S. Carver and P. P. Pandolfi, "Mouse Modeling in Oncologic Preclinical and Translational Research," Clinical Cancer Research, Vol. 12, No. 18, 2006, pp. 53055311. doi:10.1158/1078-0432.CCR-06-0482

[26] A. W. Nienhuis, C. E. Dunbar and B. P. Sorrentino, "Genotoxicity of Retroviral Integration in Hematopoietic cells," Molecular Therapy, Vol. 13, No. 6, 2006, pp. 10311049. doi:10.1016/j.ymthe.2006.03.001

[27] N. B. Woods, V. Bottero, M. Schmidt, C. von Kalle and I. M. Verma, "Gene Therapy: Therapeutic Gene Causing Lymphoma," Nature, Vol. 440, No. 7088, 2006, p. 1123. doi:10.1038/4401123a

[28] B. Calmels, C. Ferguson, M. O. Laukkanen, R. Adler, M. Faulhaber, H. J. Kim, S. Sellers, P. Hematti, M. Schmidt, C. von Kalle, K. Akagi, R. E. Donahue and C. E. Dunbar, "Recurrent Retroviral Vector Integration at the Mds1/ Evil Locus in Nonhuman Primate Hematopoietic Cells," Blood, Vol. 106, No. 7, 2005, pp. 2530-2533. doi:10.1182/blood-2005-03-1115 
[29] A. S. Kim, D. A. Eastmond and R. J. Preston, "Childhood Acute Lymphocytic Leukemia and Perspectives on Risk Assessment of Early-Life Stage Exposures," Mutation Research, Vol. 613, No. 2-3, 2006, pp. 138-160. doi:10.1016/j.mrrev.2006.09.001

[30] Y. Chalandon, X. Jiang, O. Christ, S. Loutet, E. Thanopoulou, A. Eaves and C. Eaves, "BCR-ABL-Transduced Human Cord Blood Cells Produce Abnormal Populations in Immunodeficient Mice," Leukemia, Vol. 19, No. 3, 2005, pp. 442-448. doi:10.1038/sj.leu.2403650

[31] W. C. Hahn and R. A. Weinberg, "Rules for Making Human Tumor Cells," New England Journal of Medicine, Vol. 347, No. 20, 2002, pp. 1593-1603. doi:10.1056/NEJMra021902

[32] R. Ono, H. Nakajima, K. Ozaki, H. Kumagai, T. Kawashima, T. Taki, T. Kitamura, Y. Hayashi and T. Nosaka, "Dimerization of MLL Fusion Proteins and $\mathrm{FLT}_{3}$ Activation Synergize to Induce Multiple-Lineage Leukemogenesis," Journal of Clinical Investigation, Vol. 115, No.
4, 2005, pp. 919-929.

[33] R. L. Levine, M. Wadleigh, J. Cools, B. L. Ebert, G. Wernig, B. J. Huntly, T. J. Boggon, I. Wlodarska, J. J. Clark, S. Moore, J. Adelsperger, S. Koo, J. C. Lee, S. Gabriel, T. Mercher, A. D'Andrea, S. Frohling, K. Dohner, P. Marynen, P. Vandenberghe, R. A. Mesa, A. Tefferi, J. D. Griffin, M. J. Eck, W. R. Sellers, M. Meyerson, T. R. Golub, S. J. Lee and D. G. Gilliland, "Activating Mutation in the Tyrosine Kinase JAK2 in Polycythemia Vera, Essential Thrombocythemia, and Myeloid Metaplasia with Myelofibrosis," Cancer Cell, Vol. 7, No. 4, 2005, pp. 387-397. doi:10.1016/i.ccr.2005.03.023

[34] M. Schmidt, K. Schwarzwaelder, C. Bartholomae, K. Zaoui, C. Ball, I. Pilz, S. Braun, H. Glimm and C. von Kalle, "High-Resolution Insertion-Site Analysis by Linear Amplification-Mediated PCR (LAM-PCR)," Nature Methods, Vol. 4, No. 12, 2007, pp. 1051-1057. doi:10.1038/nmeth1103 